\title{
Investigating the effects of organizational culture on brand promise
}

\author{
Hamed Abbasi ${ }^{a}$, Hamid Reza Abbasi ${ }^{b}$, Ashkan Faraji ${ }^{c^{*}}$ and Mahsan Hajirasouliha ${ }^{c}$
}

\author{
${ }^{a}$ Department of Management, Tehran Central Branch, Islamic Azad University, Central, Iran \\ ${ }^{b}$ Department of Management, Abhar Branch, Islamic Azad University, Abhar, Iran \\ ${ }^{c}$ Department of Management and Accounting, South Tehran Branch, Islamic Azad University, Tehran, Iran \\ CHR O N I C L E

\section{A B S T R A C T}

Article history:

Received July 28, 2013

Accepted 10 March 2014

Available online

March 112014

Keywords:

Brand promise

Organizational culture

Tribal culture

Entrepreneurial culture

Market culture
This paper studies the impacts of four components of organizational culture on brand promise in one of Iranian producer of detergent and sanitary products. The proposed study uses two questionnaires, one for measuring the effects of organizational culture and the other for brand promise in Likert scale. Cronbach alphas for organizational culture and brand promise are calculated as 0.83 and 0.91 , respectively. The study has been implemented among 211 regular customers of producer of detergent and sanitary products. Using Spearman correlation ratio as well as stepwise regression analysis, the study has detected that three components of organizational culture including tribal culture, entrepreneurial culture, and market culture influence positively on brand promise and bureaucratic culture influences negatively on brand promise.

\section{Introduction}

Brand plays essential role on the success of organizations and brand promises determine whether a business model is capable of providing good quality services or not. There are also some evidences to believe that organizational culture could influences on brand promises (Barney, 1986; De Chernatony \& Segal-Horn, 2003; Schein, 1984, 1990, 1992). Burmann and Zeplin (2005) presented a model for internal brand management based on the identity-based brand management approach to have a consistent and continuous identity in order to be trusted. Concentrating on the effect of employees in ensuring consistency of the brand identity, they developed two behavioral constructs where the first one, brand citizenship behavior, outlined what it means for employees to 'live the brand' and the second one, brand commitment, described the psychological processes, which lead employees to demonstrate brand citizenship behavior. Three key levers for building brand commitment and four context factors were shown as building blocks of internal brand management. The theoretical insights were complemented by various real-life instances obtained from in-depth interviews with brand managers and experts.

*Corresponding author.

E-mail addresses: ashkan.faraji1367@gmail.com (A. Faraji) 
One of the main issues most firms face in the marketplace is an existing gap between corporate brand values as perceived by the consumers and the corporate brand values declared as such by the management. One reason is the circumstances, in which firms transfer to their customers corporate brand values, which are different from their actual corporate values and culture. As a consequence, the consumer may feel a mistrust towards the corporate brand, which results in a weakened brand.

Yaniv and Farkas (2005) explained that Person-Organization Fit (POF) could play essential role in closing that gap. The notion of POF has been explored substantially and normally in association with internal organizational characteristics such as organizational commitment, organizational identification, job satisfaction, intention to quite the firm, willingness to do extra work in the organization, etc. They examined the effect of POF from quite a different aspect, an external one based on the brand perception of employees and as a consequence on the brand perception of customers. They concluded that employees' POF positively influences the extent to which they perceived their corporate brand values as congruent with those declared by the management, and that the brand perception level of employees positively influences the perception level of the customers.

de Chernatony and Cottam (2008) performed an investigation on interactions between organizational cultures and corporate brands. They looked to consider the interaction between corporate brands and organizational cultures within less successful UK financial services organizations to provide guidance about better managing corporate brands. Given the existing link between culture and employee behavior and the criticality of employee behavior in services brands, organizational culture was considered by managers and staff as being key to brand success.

\section{The proposed study}

This paper investigates the effects of three components of organizational culture on brand promise in one of Iranian producers of detergent and sanitary products. The proposed study uses two questionnaires, one for measuring the effects of organizational culture and the other for measuring the effect of brand promise in Likert scale. The proposed study considers the following four hypotheses,

1. Tribal culture influences on brand promise, positively.

2. Entrepreneurial culture influences on brand promise, positively.

3. Market culture influences on brand promise, positively.

4. Bureaucratic culture influences on brand promise, negatively.

Fig. 1 shows the structure of the proposed study as follows,

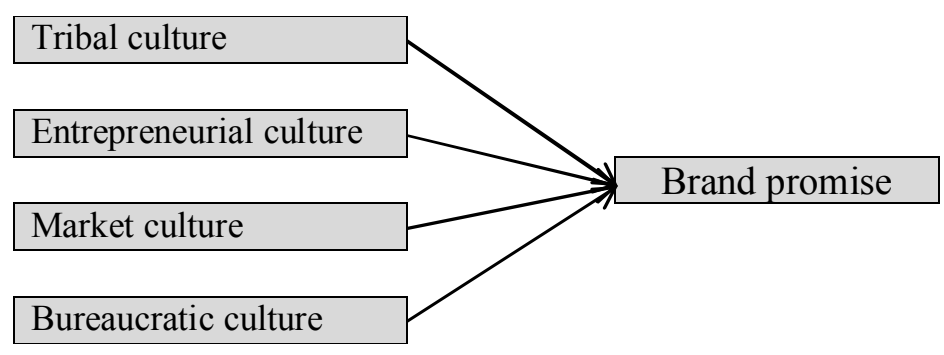

Fig. 1. The proposed study

Cronbach alphas for organizational culture and brand promise are calculated as 0.83 and 0.91 , respectively. The study has been implemented among some experts in detergent industry. The sample size is calculated as follows,

$N=Z_{\alpha / 2}^{2} \frac{p \times q}{e^{2}}$, 
where $N$ is the sample size, $p=1-q$ represents the probability, $z_{\alpha / 2}$ is CDF of normal distribution and finally $\varepsilon$ is the error term. For our study we assume $p=0.5, z_{\alpha / 2}=1.96$ and $e=0.05$, the number of sample size is calculated as $N=210$. We have distributed the questionnaires among some participants and Fig. 2 demonstrates personal charactersitcs of the participants.

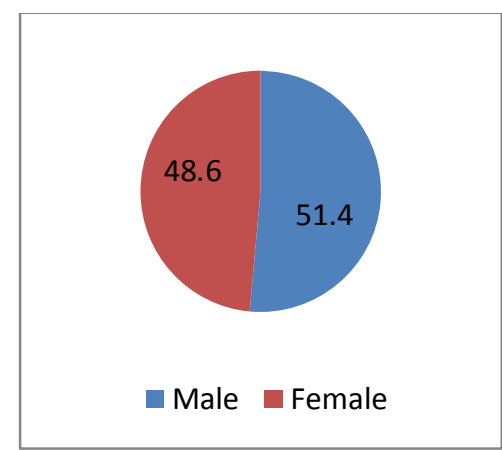

Gender

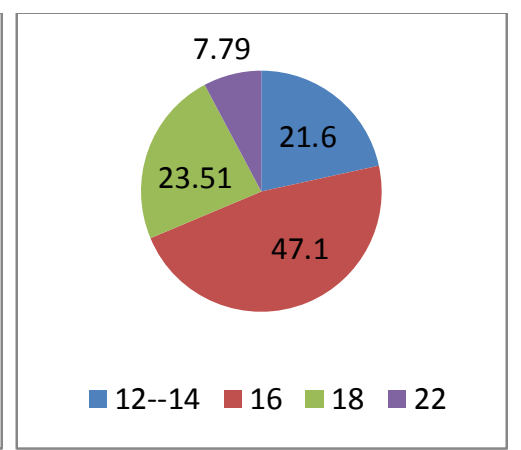

Years of education

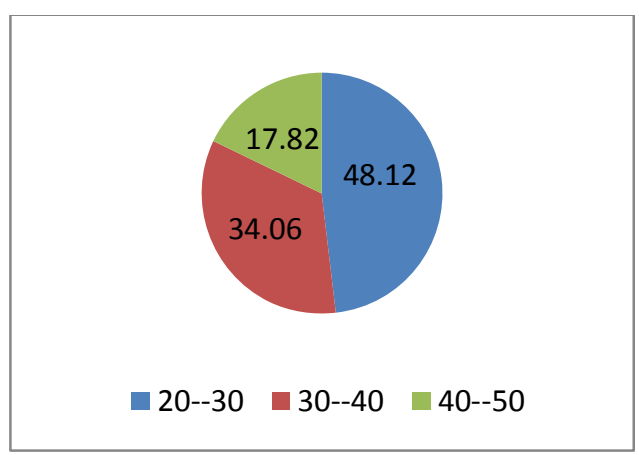

Age

Fig. 2. Personal characteristics of the participants

As we can observe from the results of Fig. 3, 51.4\% of the participants were male and the remaining $48.6 \%$ of them were female. In terms of educational background, most participants had some university background. Finally, the survey indicates that most people who took part in our survey were young and middle aged people. The implementation of Kolmogorov-Smirnove test implies the data are not normally distributed. Therefore, we use Spearman correlation ratio as well as Stepwise regression test to verify the hypotheses of the survey.

\section{The results}

In this section, we give details of our results on testing four hypotheses of the survey. Table 1 shows the results of Spearman correlation ratio on testing the effects of four organizational culture components on brand promise.

\section{Table 1}

The results of examining the effect of organizational culture on brand promise using Spearman correlation

\begin{tabular}{llccc}
\hline Hypothesis & Relationship & r & Sig. & Result \\
\hline First & Tribal culture $\rightarrow$ Brand promise & 0.461 & 0.000 & Confirmed \\
Second & Entrepreneurial culture $\rightarrow$ Brand promise & 0.409 & 0.020 & Confirmed \\
Third & Market culture $\rightarrow$ Brand promise & 0.253 & 0.050 & Confirmed \\
Fourth & Bureaucratic culture $\rightarrow$ Brand promise & -0.327 & 0.000 & Confirmed \\
\hline
\end{tabular}

The results of Table 1 indicate that there were three positive and meaningful relationships between components of organizational culture and brand promise when the level of significance is five percent. The highest correlation is between tribal culture and brand promise $(\mathrm{r}=0.461$, Sig. $=0.000)$ followed by the relationship between entrepreneurial culture and brand promise $(\mathrm{r}=0.409$, Sig. $=$ $0.020)$ and between market culture and brand promise $(r=0.253$, Sig. $=0.050)$. In addition, there was a negative and meaningful relationship between bureaucratic culture and brand promise $(\mathrm{r}=-0.327$, Sig. $=0.000)$. We have also performed stepwise regression analysis and Table 2 shows the results of the survey. 
Table 2

The summary of stepwise regression analysis

\begin{tabular}{|c|c|c|c|c|c|}
\hline Variable & Coefficient & Standard error & Standard coefficient & t-value & P-value \\
\hline Intercept & 60.139 & 3.183 & & 21.854 & .000 \\
\hline Tribal culture & .582 & .236 & .394 & 3.901 & .000 \\
\hline Entrepreneurial culture & .517 & .201 & .314 & 3.379 & .002 \\
\hline Bureaucratic culture & -.464 & .158 & -.275 & -2.053 & .016 \\
\hline
\end{tabular}

As we can observe from the results of Table 2, two organizational justice including Tribal culture and Entrepreneurial culture influence positively on brand promise $(\alpha=0.05)$ while Bureaucratic culture influences negatively on brand promise.

\section{Conclusion}

In this paper, we have presented an empirical study to determine the impacts of organization culture on brand promise in Iranian detergent industry. The study has distributed two questionnaires among some experts and using Spearman correlation ratios as well as stepwise regression analysis, we have determined that two organizational culture including tribal culture and entrepreneurial culture influence positively on brand promise $(\alpha=0.05)$. In addition, the study has determined that bureaucratic culture influenced negatively on brand promise.

\section{Acknowledgement}

The authors would like to thank the anonymous referees for their comments on earlier version of this paper.

\section{References}

Barney, J. B. (1986). Organizational culture: can it be a source of sustained competitive advantage?. Academy of management review, 11(3), 656-665.

Burmann, C., \& Zeplin, S. (2005). Building brand commitment: A behavioural approach to internal brand management. The Journal of Brand Management,12(4), 279-300.

De Chernatony, L., \& Segal-Horn, S. (2003). The criteria for successful services brands. European Journal of Marketing, 37(7/8), 1095-1118.

de Chernatony, L., \& Cottam, S. (2008). Interactions between organisational cultures and corporate brands. Journal of Product \& Brand Management, 17(1), 13-24.

Schein, E. H. (1984). Coming to a new awareness of organizational culture.Sloan management review, 25(2), 3-16.

Schein, E. H. (1990). Organizational culture (Vol. 45, No. 2, p. 109). American Psychological Association.

Schein, E. H. (1992). Coming to a new awareness of organizational culture (pp. 237-54). Sage.

Yaniv, E., \& Farkas, F. (2005). The impact of person-organization fit on the corporate brand perception of employees and of customers. Journal of Change Management, 5(4), 447-461. 